\title{
Correction
}

Ophthalmologe $2018 \cdot 115: 669$

https://doi.org/10.1007/s00347-017-0621-9

Online publiziert: 7. Dezember 2017

(c) Springer Medizin Verlag $\mathrm{GmbH}$, ein Teil von Springer Nature 2017

CrossMark
C. V. Fischer $\cdot$ M. Kulanga $\cdot$ H. Hoerauf

Klinik für Augenheilkunde, Universitätsmedizin Göttingen, Göttingen, Deutschland

\section{Correction: Trends in der Ablatiochirurgie}

\section{Was hat sich im Vergleich zu 2001 geändert?}

\section{Correction:}

Ophthalmologe 2017

https://doi.org/10.1007/s00347-017-

0559-y

Sehr geehrter Leser, sehr geehrte Leserin,

die Onlineversion dieses Artikels wurde geändert: leider wurde der Beitrag mit fehlerhaftem englischen Titel veröffentlicht.

Wir bitten, den korrekten englischen Titel Trends in retinal detachment surgery. What has changed compared to 2001? zu berücksichtigen und den Fehler zu entschuldigen.

Die Redaktion

\section{Korrespondenzadresse}

\section{Dr. C. V. Fischer}

Klinik für Augenheilkunde, Universitätsmedizin Göttingen

Robert-Koch-Str. 40, 37075 Göttingen,

Deutschland

c.fischer@med.uni-goettingen.de 